\title{
GERENCIAMENTO DOS RESÍDUOS DA CONSTRUÇÃO E DEMOLIÇÃO: DIRETRIZES PARA O CRESCIMENTO SUSTENTÁVEL DA CONSTRUÇÃO CIVIL NA REGIÃO METROPOLITANA DO CARIRI CEARENSE
}

Jefferson Luiz Alves Marinho ${ }^{1}$

Joel Dias da Silva²

\section{RESUMO}

O crescimento da população, os avanços da indústria e da urbanização contribuíram para o aumento da geração de Resíduos da Construção e Demolição - RCD que são lançados no meio ambiente, como apontam dados levantados em diversas cidades brasileiras onde o RCD representa mais de $50 \%$ da massa de resíduos sólidos urbanos. A indústria da construção apresenta particularidades, e, dentre suas principais características estão o elevado desperdício e o grande impacto ambiental provocado pelo volume de resíduos gerados e pela grande quantidade de matéria-prima consumida, sendo motivo de diversas discussões quanto à necessidade de se buscar o desenvolvimento sustentável. Este trabalho vem contribuir para a solução dessa problemática, mais especificamente no que diz respeito ao combate à geração de resíduos, na medida em que faz um diagnóstico e apresenta algumas diretrizes para o crescimento sustentável da construção civil na Região Metropolitana do Cariri - RMC. A metodologia utilizada no trabalho consistiu na pesquisa bibliográfica, identificação dos principais pontos de deposição e estimativa da quantidade dos RCD, identificação dos impactos ambientais provocados pela deposição irregular dos RCD e cumprimento da Legislação Ambiental vigente no âmbito Federal, Estadual e Municipal. Para obtenção de dados foram aplicados questionários, feitas entrevistas, visitas exploratórias e registros fotográficos. Os principais resultados obtidos da pesquisa demonstram que os diversos atores sociais envolvidos na questão ambiental da região estudada possuem um conhecimento modesto da Legislação Ambiental específica e que a maior parte dos entrevistados não sabe o destino dos RCD produzidos em suas obras.

Palavras-chave: Resíduos da Construção Civil e Demolição. Gestão. Impactos Ambientais. Desenvolvimento Sustentável.

\footnotetext{
${ }^{1}$ Mestre; e-mail: engeap@gmail.com

2Doutor e-mail: dias_joel@hotmail.com
} 


\section{INTRODUÇÃO}

A falta de uma política adequada para a destinação do grande volume dos resíduos sólidos gerados através das atividades do setor da construção civil, que no Brasil é estimado em 68,5 milhões de tonelada por ano, Freitas (2009), tem desafiado os gestores públicos no sentido de encontrarem soluções para estes problemas, sempre na busca de minimizar os danos ao meio ambiente. No Brasil, o art. 225 da Constituição Federal de 1988, prevê que "todos têm direito a um meio ambiente ecologicamente equilibrado, bem de uso comum do povo e essencial à sadia qualidade de vida [...]". (BRASIL, 1988).

Diante desta previsão legal do nosso ordenamento jurídico, a preocupação com o gerenciamento de resíduos da construção civil vem se consolidando como uma prática importante dentro da concepção de desenvolvimento sustentável, uma vez que a grande quantidade de resíduos gerados nas atividades da construção civil (construções, reformas, ampliações e demolições) e sua consequente destinação final, quando não realizadas em conformidade com as diretrizes estabelecidas pela Resolução n. 307, de 05 de Julho de 2002, do Conselho Nacional de Meio Ambiente - CONAMA (BRASIL, 2002) podem resultar em impactos ambientais graves podendo se manifestar entre outros aspectos através dos alagamentos, deslizamentos de encostas, degradação de áreas de preservação permanente, assoreamento de córregos e rios, obstrução de vias e logradouros públicos, proliferação de vetores de doenças, queimadas entre outros, que tantos malefícios causam à população e ao meio ambiente.

A indústria da construção civil apresenta particularidades, e, dentre suas principais características estão o elevado desperdício e o grande impacto ambiental gerado em termos de volume de resíduos gerados e matéria-prima consumida. A maioria dos profissionais da construção civil ignora a quantidade de resíduos sólidos gerados a partir da demolição e construção de obras civis e, quando conscientes da poluição ambiental, não estão orientados de como fazer uma destinação seletiva dos resíduos, através de uma deposição correta e de uma triagem, separando os resíduos passíveis de reciclagem e/ou reutilização. A prática da reciclagem dos resíduos oriundos da construção civil é muito importante para a sustentabilidade da nossa sociedade, porque ela está diretamente relacionada com atenuação do impacto ambiental gerado pelo setor e redução de custos de gerenciamento do resíduo. Estima-se que o setor é responsável por consumir cerca de $20 \%$ a $50 \%$ do total de recursos naturais utilizados pela sociedade (FREITAS, 2009; SANTOS, 1995).

Para isso, se faz necessário uma eficiente gestão das atividades que envolvem a indústria da construção civil, como forma de se atenuar os problemas ecológicos uma vez que além de consumir uma enorme quantidade de recursos naturais, gera e descarta toneladas de Resíduos da Construção e Demolição - RCD, não fechando seu ciclo produtivo, causando com isso, gravíssimos impactos ambientais e sanitários. Partindo-se da ideia de tentar "fechar" o ciclo produtivo da indústria da construção, já foi falado sobre coleta seletiva, armazenagem e reciclagem. Quanto ao reuso do RCD e seu reaproveitamento já existem várias tecnologias e experiências bem sucedidas (GAEDE, 2006). 
De acordo com a publicação Guia de Sustentabilidade na Construção do Sindicato da Indústria da Construção Civil-MG (2008, p. 32), "sob a perspectiva da sustentabilidade, materiais e resíduos devem ser tratados conjuntamente, uma vez que a correta seleção e utilização de materiais reduzem a geração de resíduos e os impactos por ela ocasionados" e reforça adiante:

\begin{abstract}
um eficaz projeto de gerenciamento de resíduos da construção deve começar ainda na fase de projeto. Quando possível, especificar materiais e sistemas construtivos com baixo impacto ambiental, podendo inclusive privilegiar materiais que gerem resíduos não perigosos em detrimento aos perigosos e contaminantes. (SINDICATO DA INDÚSTRIA DA CONSTRUÇÃO CIVIL-MG, 2008, p. 48).
\end{abstract}

O desenvolvimento sustentável deve representar mudanças na maneira como exploramos os recursos naturais, aliadas à utilização de inovações tecnológicas, para o melhor aproveitamento dos resíduos gerados atendendo de maneira satisfatória às aspirações e demandas da população no presente e no futuro. Desta forma, observa-se a relevância do tema da pesquisa e o seu enquadramento na construção sustentável, que tem como base o uso consciente dos recursos naturais e a gestão dos resíduos de construção e demolição.

Com o incremento das atividades do setor da construção civil motivado pela urbanização acelerada e pelo rápido adensamento das cidades que compõem a Região do Cariri Cearense, a geração dos RCD alcançou volumes alarmantes, onde se estima que seja superior ao percentual registrado por Medeiros (1995) para as grandes cidades brasileiras, que é de $50 \%$ do peso total de Resíduos Sólidos Urbanos - RSU produzidos diariamente, uma vez que não existe uma política de gerenciamento dos RCD e nem tampouco usinas de reciclagem. Fato que chamou a atenção de ambientalistas que defendem um crescimento sustentável da Região do Cariri.

Não se pode olvidar que a ausência de tratamento adequado dos RCD acarreta graves problemas ambientais e sociais, pois quando dispostos de forma inadequada, como se verifica na área estudada, geram a degradação da qualidade de vida urbana, podendo se manifestar entre outros aspectos através dos alagamentos, deslizamentos de encostas e proliferação de vetores de doenças. Mais recentemente, com a tendência de construções sustentáveis, o interesse pelos RCD tem acirrado o debate acadêmico e aumentado o interesse dos pesquisadores, uma vez que desperdiçar quer sob a ótica da geração de resíduos, quer sobre outra perspectiva, significa desperdiçar recursos naturais, o que contribui para colocar o desenvolvimento sustentável como meta principal a ser alcançada pela indústria da construção civil.

A Região Metropolitana do Cariri destaca-se por apresentar um forte crescimento econômico, social, educacional e cultural. No tocante ao crescimento da construção civil na região, segundo dados do Conselho Regional de Corretores de Imóveis - CRECI Subseção Cariri é de torno de $30 \%$ ao ano, o que se contrapõe aos graves impactos causados pela grande quantidade de RCD que são depositados, clandestinamente em 
terrenos baldios, áreas de preservação permanente, margens e nascentes de córregos. A região, como a maioria das grandes cidades brasileiras, não possui espaços destinados ao recebimento adequados dos RCD, conhecidos na literatura especializada como Pontos de Entrega Voluntária de Resíduos de Construção Civil, ou mais popularmente como "Bolsões de Entulho". Esses espaços são definidos como sendo áreas licenciadas e capacitadas para o recebimento, e triagem e destinação final correta desses resíduos para a Usina de Reciclagem de Resíduos de Construção Civil. O grande volume de resíduos dispensados pela construção civil gera impactos ambientais significativos por sua disposição de forma incontrolada e sem critérios científicos. De acordo com Marques Neto (2005) apud Ferreira, Noschang e Ferreira (2009, p. 18) os impactos ambientais mais comuns são:

\begin{abstract}
a) Formação de áreas irregulares de descarte e o esgotamento dos "bota-foras" com a disposição de grandes volumes de resíduos que afetam diretamente as condições de tráfego de pedestres e veículos, a drenagem superficial e a obstrução de córregos que propiciam a multiplicação de vetores e doenças.
\end{abstract}

b) Áreas, que pela maneira irregular da deposição, servem de atrativo para a disposição de outros materiais de origem industrial e domésticos, nem sempre inertes que incrementam o impacto ambiental.

c) Construtores clandestinos de pequenas obras lançam os resíduos ao longo das estradas, das vias públicas, terrenos baldios e nas margens de rios e córregos agravando os problemas urbanos como enchentes e tráfego congestionado.

d) Locais irregulares de disposição de RCD e outros materiais propiciam a degradação de áreas que deveriam ser preservadas, bem como, degradam os espaços urbanos.

Neste contexto, o desenvolvimento deste trabalho justifica-se pelo fato de ainda serem incipientes os estudos a cerca dos RCD na Região Metropolitana do Cariri, onde as evidências apontam para a necessidade de um planejamento que se preocupe com a gestão dos resíduos, sobretudo nas áreas periféricas onde a probabilidade de deposição irregular aumenta com a ocupação desordenada. Além de que se consubstanciará num instrumento valioso para propiciar meios aos setores competentes, aos gestores municipais e/ou estaduais da região e, mais especificamente, aos empresários da construção civil, para a adoção de medidas específicas que possibilitem estratégias que viabilizem a ocupação ordenada, a urbanização racional da Região Metropolitana do Cariri, assegurando o desenvolvimento sustentável e melhorando a qualidade de vida da população. 


\section{DESENVOLVIMENTO}

\subsection{Metodologia}

Fez-se uso da seguinte metodologia de pesquisa:

a) Realização de vasta revisão teórica sobre a temática dos RCD;

b) Visitas a canteiros de obras espalhados pela Região Metropolitana do Cariri, visando identificar os RCD produzidos;

c) Visitas aos locais de deposição irregular dos RCD;

d) Visitas a empresas coletoras de RCD;

e) Visitas a órgãos ambientais da Região Metropolitana do Cariri;

f) Estimativa do volume de RCD coletados pelas empresas de coleta;

g) Aplicação de checklist nos canteiros de obras pesquisados e em três empresas coletoras de RCD, com os seguintes questionamentos:

_ Para a obtenção dos dados referentes aos canteiros de obras pesquisados, foi elaborado o seguinte checklist:

1) Você conhece o teor da Resolução no 307 do CONAMA?

2) Nesta obra há algum Programa de Gerenciamento de Resíduos Sólidos?

3) Você tem conhecimento do local de destino final dos RCD gerados por esta obra? Em caso afirmativo, qual o destino final dos RCD?

4) Nesta obra há sistema de coleta seletiva de resíduos?

5) Dentre as opções abaixo indique o impacto causado pela geração dos RCD desta obra. ( ) Baixo ( ) Médio ( ) Alto ( ) Muito Alto

_ Para a obtenção dos dados referentes aos canteiros de obras pesquisados, foi elaborado o seguinte checklist:

1) Qual a área de atendimento da sua empresa?

2) Qual a média de caçambas coletas por mês?

3) Quantos containers esta empresa possui?

4) Qual o local de despejo dos RCD? 
5) Sabe se na cidade existe alguma área de despejo autorizada pela Prefeitura Municipal?

6) Há uma segregação dos resíduos coletados antes do descarte?

7) Há licenciamento ambiental?

8) Você conhece o teor da Resolução no 307 do CONAMA?

\subsection{Resultados Obtidos}

Diversos impactos negativos advindos das deposições irregulares de RCD foram observados. Destaca-se primeiramente, a degradação da paisagem natural no entorno das áreas de deposição, o que causa sensação de desconforto para quem passa por estes locais e indubitavelmente, afetam também a população local, pois é desagradável a visão de resíduos despejados nos terrenos baldios, ao longo de avenidas ou junto a estradas. Esta situação é particularmente muito adversa pela formação de amontoados de entulho que vão se acumulando às margens das vias. Outro sério problema é que tais áreas são pólos de atração, não só de RCD, mas de outros tipos de resíduos. São atraídos resíduos volumosos (móveis e eletrodomésticos velhos, por exemplo), galhadas (restos de poda ou corte de árvores), resíduo domiciliar, resíduos industriais e muitos outros. Como resultado tem-se a poluição do solo, podendo-se inclusive deduzir que haja contaminação, em decorrência da presença de resíduos não inertes.

Enfim, a atividade de deposição de resíduos na Região Metropolitana do Cariri, assim como é conhecido em outras áreas de deposição, tem contribuído com a degradação do ambiente urbano e perda de qualidade de vida dos moradores dessas cidades, demonstrando a necessidade de intervenções que incluam a adoção de novos métodos mais sustentáveis na gestão pública dos RCD.

A visita exploratória nas nove cidades da Região Metropolitana do Cariri, realizada no período de abril a junho de 2011, orientou o mapeamento das áreas ou pontos onde haviam sido detectados os maiores volumes de resíduos. O mapeamento desses pontos mostrou a existência de uma quantidade expressiva de resíduos de toda sorte, descartados irregularmente em vários pontos da área estudada. Também foi possível verificar que além da utilização de áreas públicas e vias de trânsito, a deposição irregular de RCD ocorre por invasão de áreas privadas, conforme ilustrado na Figura 1, que mostra o entulho em um terreno particular situado no Bairro da Lagoa Seca, em Juazeiro do Norte. 


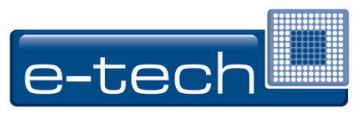

Figura 1: Disposição irregular de resíduos no bairro Lagoa Seca em Juazeiro do Norte

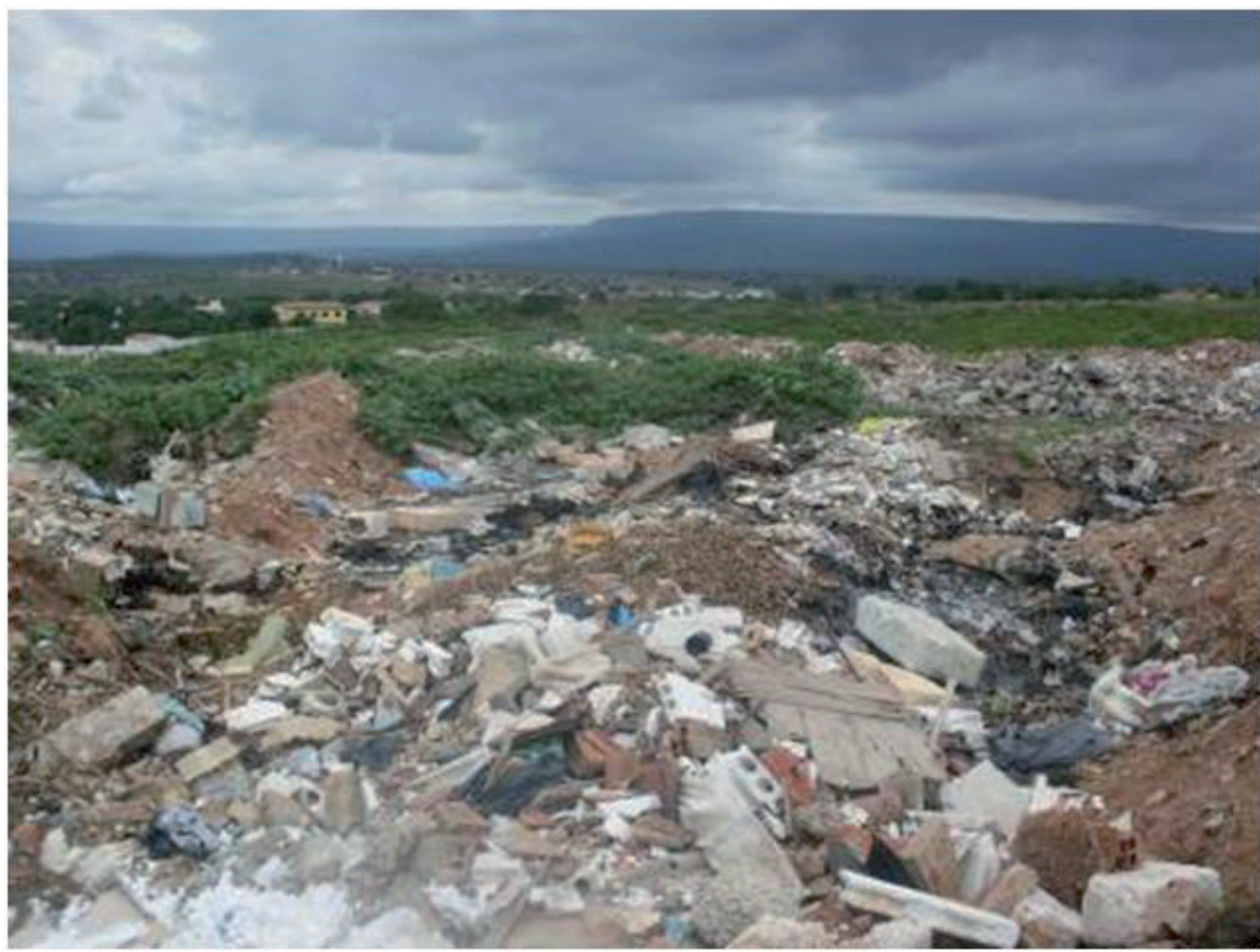

Fonte: Dos autores (2011)

Durante a pesquisa constatou-se a existência de 24 (vinte e quatro) pontos de disposição irregular na Região Metropolitana do Cariri, conforme se pode constatar na Tabela 1.

Tabela 1: Distribuição dos pontos de disposição irregular dos RCD na área de estudo

\begin{tabular}{l|l}
\hline Cidades & $\mathbf{N}^{\circ}$ de pontos \\
\hline Barbalha & 02 \\
Caririaçu & 02 \\
Crato & 04 \\
Farias Brito & 01 \\
Jardim & 01 \\
Juazeiro do Norte & 08 \\
Missão Velha & 02 \\
Nova Olinda & 02 \\
Santana do Cariri & 02 \\
\hline
\end{tabular}

Fonte: Dos autores (2011) 
No tocante à disposição regular de RCD, segundo informações das prefeituras dos Municípios de Crato, Juazeiro do Norte e Barbalha, a única área pública autorizada para receber os RCD é o aterro sanitário municipal, servindo como material de cobertura dos demais RSU. O aterro sanitário da cidade de Crato se localiza na saída para o distrito de Ponta da Serra distante $6 \mathrm{~km}$ do centro comercial urbano; na cidade de Juazeiro do Norte se localiza as margens da estrada que liga a cidade ao Município de Caririaçu distando $5 \mathrm{~km}$ do centro comercial urbano e na cidade de Barbalha situa-se nas proximidades da Itapuí - Indústria de Cimentos distante $4 \mathrm{~km}$ da sede. A distância dos aterros ao centro comercial urbano dificulta que carroceiros se desloquem para lá a fim de despejar os RCD coletados por ele, fato este que propicia o aumento de pontos de deposição irregular.

Ovolume de resíduos proveniente de reformas e demolições e descartados irregularmente foi estimado a partir de dados fornecidos pelas empresas coletoras de RCD da Região Metropolitana do Cariri, sendo recolhidos em torno de 630 containeres de $5 \mathrm{~m}^{3}$ por mês, conforme tabela 2.

Tabela 2: Quantidade de RCD coletados pelas empresas especializadas

\begin{tabular}{l|l|l}
\hline $\begin{array}{l}\text { Empresas Coletoras } \\
\text { de RCD }\end{array}$ & Cidade da RMC & $\begin{array}{l}\text { Quantidade de container } \\
\text { de RCD coletado/mês }\end{array}$ \\
\hline Empresa 1 & Juazeiro do Norte & 200 \\
Empresa 2 & Juazeiro do Norte & 250 \\
Empresa 3 & Crato & 300 \\
Total de Caçambas & & 750 \\
\hline
\end{tabular}

Fonte: Dos autores (2011)

Verificou-se também que, excluindo-se as cidades de Crato, Juazeiro do Norte e Barbalha, em todas as demais cidades da Região Metropolitana do Cariri os RCD são, em sua maioria, utilizados como lastro (aterro) para estradas vicinais que ligam a sede do município aos Distritos e Vilarejos da zona rural destas cidades. Foram identificados oito (08) pontos de deposições irregulares na cidade de Juazeiro do Norte, os quais foram identificados e mapeados, conforme Figura 2. 
Figura 2: Disposição irregular de RCD
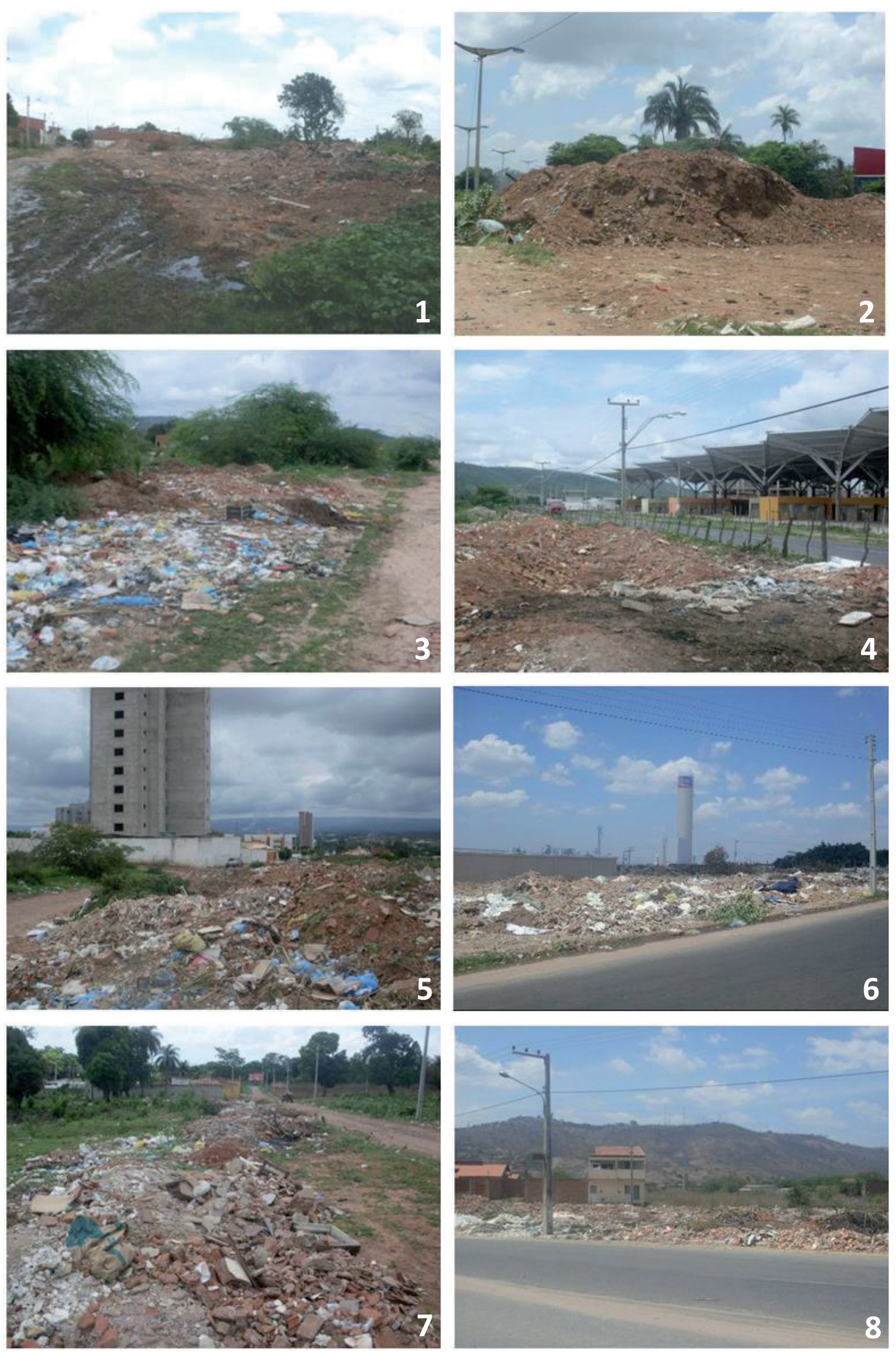

Fonte: Dos autores (2011) 


\section{Legenda:}

1) Área de deposição de RCD às margens da Av. José Bezerra no Bairro Timbaúbas, em Juazeiro do Norte/CE.

2) Área de deposição de RCD às margens da Av. Antônio Pereira da Silva, Bairro José Geraldo da Cruz em Juazeiro do Norte/CE.

3) Área de deposição de RCD às margens da Av. Prefeito Carlos Cruz no acesso à Vila Carité em Juazeiro do Norte/CE.

4) Área de deposição de RCD às margens da Av. do Agricultor (em frente ao Centro de apoio ao Romeiro), Bairro centro, em Juazeiro do Norte/CE.

5) Área de deposição de RCD na Rua Maria Diva de Carvalho, próximo ao Edifício Mirante do Cariri, Bairro Lagoa Seca em Juazeiro do Norte/CE

6) Área de deposição de RCD na Rua João F. Lustosa, nas imediações do Juazeiro Open Mall, Bairro Santa Tereza em Juazeiro do Norte/CE.

7) Área de deposição de RCD na Rua Francisca Paula Bezerra, Bairro Limeiro em Juazeiro do Norte/CE.

8) Área de deposição de RCD às margens da Av. José de Melo, Bairro Salgadinho em Juazeiro do Norte/CE.

De acordo com Tavares (2007), o setor da construção civil vem tomando atitudes que visam minimizar os impactos ao meio ambiente em resposta às pressões regulamentadoras e da própria sociedade. Essas atitudes se traduzem numa busca de resultados satisfatórios em processos como a reciclagem, a redução de energia e a redução de perdas.

Em relação à Região Metropolitana do Cariri, a quantidade de RCD existente é bastante preocupante, como se pode observar através das visitas realizadas aos 24 (vinte e quatro) pontos de disposição irregular dos RCD, sendo que essa disposição incorreta é agravada pelas precárias condições sanitárias e ausência de práticas de Educação Ambiental. De acordo com a Secretaria de Meio Ambiente e Serviços Públicos da cidade de Juazeiro do Norte/CE, não existem dados sistematizados e nem controle dos RCD gerados no Município.

Assim, para se estimar a quantidade de resíduos coletados em caçambas tomou-se como base o valor médio adotado nos estudos de Carneiro et al. (2001), que é de $1.156 \mathrm{~kg} / \mathrm{m}^{3}$, permitindo chegar ao valor quantitativo de entulho para as cidades de Crato e Juazeiro do Norte de acordo com a população das mesmas para o ano de 2012: 
a) Estimativa do volume de RCD na cidade de Crato/CE:

Coleta mensal $=300$ containers $\times 5 \mathrm{~m}^{3} \times 1.156 \mathrm{~kg} / \mathrm{m}^{3}=1.734 \mathrm{t} / \mathrm{mês}$;

Coleta diária $=1.734 \mathrm{t} / \mathrm{mês} / 26$ dias $=66,69 \mathrm{t} / \mathrm{dia} \approx 67 \mathrm{t} . \mathrm{d}-1 ;$

Coleta diária $/ \mathrm{hab}=67.000 \mathrm{~kg} \cdot \mathrm{d}-1 / 116.759=0,57 \mathrm{~kg} / \mathrm{hab} \cdot \mathrm{d}-1$ de RCD.

b) Estimativa do volume de RCD na cidade de Juazeiro do Norte/CE

Coleta mensal $=450$ containers $\times 5 \mathrm{~m}^{3} \times 1.156 \mathrm{~kg} / \mathrm{m}^{3}=2.601 \mathrm{t} / \mathrm{mês}$;

Coleta diária $=2.601 \mathrm{t} / \mathrm{mês} / 26$ dias $=100,041 \mathrm{t} \cdot \mathrm{d}^{-1} \approx 100 \mathrm{t} \cdot \mathrm{d}^{-1}$

Coleta diária $/$ hab: $100.000 \mathrm{~kg} / \mathrm{dia} / 249.829=0,42 \mathrm{~kg} / \mathrm{hab} \cdot \mathrm{d}^{-1}$ de RCD.

c) Estimativa do volume médio de RCD na RMC

Coleta diária $/ \mathrm{hab}=167.000 \mathrm{~kg} \cdot \mathrm{d}^{-1} / 366.588=0,455 \mathrm{~kg} / \mathrm{hab} \cdot \mathrm{d}^{-1} \mathrm{de}$ RCD;

Coleta anual $/ \mathrm{hab}=0,45 \mathrm{~kg} / \mathrm{hab} \times 360=164 \mathrm{~kg} / \mathrm{hab} / \mathrm{ano}=0,16 \mathrm{t} / \mathrm{hab} / \mathrm{ano}$.

De acordo com Pinto (1995) no Brasil são gerados em torno de 0,55 t/ano/hab de RCD. Na Região Metropolitana do Cariri foi encontrada uma taxa de 0,16 t/hab/ano, que levando em conta o fato de ser uma região do Nordeste Brasileiro onde o crescimento imobiliário ainda é modesto quando comparado com as cidades de mesmo porte das regiões Sul e Sudeste do Brasil, deve ser considerada preocupante no que concerne à forma de descarte dos RCD na área estudada. A disposição irregular de RCD demonstra falta de compromisso com a qualidade ambiental comprometendo a sustentabilidade de forma extremamente negativa. Alguns dos impactos visíveis revelam um extenso comprometimento da qualidade do ambiente e da paisagem local, onde se verifica a disposição inadequada dos resíduos nos passeios e logradouros públicos obstruindo as vias de tráfego de pedestres e de veículos.

Verificou-se ainda que, em vários bairros das cidades que compõem a Região Metropolitana do Cariri há a presença de resíduos da construção civil em áreas inadequadas contribuindo para a poluição visual e do ar, sendo essa última, na visão de Marques Neto (2005), a causa principal de vários tipos de doenças respiratórias que acometem os moradores de áreas próximas a local de disposição irregular de RCD. No que concerne aos RCD, à legislação brasileira ainda é pouco expressiva, se comparada com as vigentes em outros países (ÂNGULO, 2005). No entanto, a Resolução $n^{\circ}$ 307/02 do Conselho Nacional do Meio Ambiente (2002), representa um marco neste sentido, pois estabeleceu diretrizes, critérios e procedimentos para a gestão de resíduos da construção civil, disciplinando as ações necessárias de forma a minimizar os impactos ambientais, tendo para esse fim definido as especificações de resíduos da construção civil. De acordo com Santos (2007), este dispositivo legal além de regulamentar os RCD, atribui responsabilidades aos geradores, transportadores e gestores públicos. Antes de 
sua publicação, não existia nenhum instrumento que regulamentasse a disposição dos RCD em âmbito nacional.

A história do Direito Ambiental no Ceará é marcada por legislações que asseguram à população em geral prerrogativas que contribuem para a conservação do meio ambiente, sendo que a primeira lei que abordou a questão ambiental de forma sistêmica foi a Lei Estadual n. ${ }^{\circ} 11.411$, de 28 de Novembro de 1987, que dispõe sobre a Política Estadual do Meio Ambiente e cria o Conselho Estadual do Meio Ambiente (COEMA) e a Superintendência Estadual do Meio Ambiente (SEMACE).

Com a promulgação da Constituição Federal de 1988, de acordo com o art. 23 é competência comum da União, dos Estados e do Distrito Federal e dos Municípios, dentre outras, proteger o meio ambiente e combater a poluição em qualquer de suas formas (BRASIL, 1988).

A partir desta prerrogativa dada pela Constituição aos Estados-Membros, ocorreu no Ceará a edição de uma série de leis e decretos na área do direito ambiental. Destacamse a Lei Estadual n. ${ }^{\circ} 11.423$ de 08 de Janeiro de 1988 que proíbe no território cearense o depósito de rejeitos radioativos; a Lei Estadual n. ${ }^{\circ} 11.482$ de 20 de Julho de 1988 que proibiu, no âmbito do Estado, uso de sprays que contivessem o clorofluorcarbono (CFC); a Lei Estadual n. ${ }^{\circ} 11.996$ de 24 de Julho de 1992 que instituiu a Política Estadual de Recursos Hídricos/Sistema Integrado de Gestão de Recursos Hídricos - SIGERH e decretos como: Decreto n. ${ }^{\circ}$ 20.067/89 que criou o Regimento Interno do COEMA; Decreto n. ${ }^{\circ}$ 20.252/89 que delimitou as faixas de proteção de 1a e 2a categorias da sub-bacia B-2 do Rio Cocó; Decreto n. 20.253 que criou o Parque Ecológico do Cocó; Decreto . $^{\circ} 21.349 / 91$ e Decreto $n .^{\circ} 21.350 / 91$ que criaram a área de preservação da Lagoa da Maraponga e, por último, o Decreto n. ${ }^{\circ} 22.485 / 93$ que aprovou o Regulamento da Secretaria de Recursos Hídricos.

De maneira geral as leis ambientais estaduais vigentes no Estado do Ceará, tratam de forma global o setor do saneamento básico onde se incluem os resíduos sólidos, porém, não tratando especificamente o caso dos RCD. O que se pode constatar é que em nenhuma das sete cidades que compõem a região metropolitana do Cariri existe uma legislação municipal no que concerne aos resíduos de construção e demolição. O que existe é apenas uma previsão de multa para a colocação de entulhos junto aos passeios e logradouros públicos, contida nos códigos de postura dos Municípios de Crato, Juazeiro do Norte e Barbalha. A demais cidade que compõe a Região Metropolitana do Cariri não tem nenhuma previsão legal que discipline o acondicionamento, coleta e deposição dos RCD.

A seguir, procedeu-se a aplicação do check list em 25 canteiros de obras espalhados pelas diversas cidades do Cariri, e pertencentes a 20 construtoras distintas. A maioria das construtoras visitadas (12) afirmou ter conhecimento da Resolução $n^{\circ} 307$ do CONAMA, sendo que destas, apenas quatro (04) disseram saber que a referida Resolução se refere ao combate à geração de resíduos, porém, não tinham conhecimento do seu teor, e quatro (04) delas sequer ouviram falar da Resolução $n^{\circ}$ 407. Quanto à existência de 
algum programa de Gerenciamento de Resíduos Sólidos apenas duas empresas das vinte pesquisadas afirmaram ter em execução algum tipo de gerenciamento em execução em seus canteiros. Mas quando interrogadas sobre algum tipo de coleta seletiva de resíduos em seus canteiros, três empresas afirmaram que sim, sendo que foi constatado que apenas em dois canteiros de uma única empresa havia recipientes para coleta seletiva de resíduos (papel, metal, plástico) e baias para metralhas (restos de tijolos blocos e telhas) e restos de madeira.

No tocante ao destino dos RCD, 70\% das empresas entrevistadas não hesitaram em afirmar que a deposição irregular dos RCD tem afetado gravemente o meio ambiente, mas quando interrogados se sabiam do destino dos resíduos produzidos em suas obras, somente duas empresas afirmaram saber que destino final recebia os resíduos produzidos em seus canteiros de obras.

Sobre o impacto ao meio ambiente gerado pelos resíduos produzidos em suas obras, todas as opções previstas no questionário (baixo, médio, alto e muito alto) foram citadas pelo menos por uma das empresas, como se pode observar na Figura 3. Verificou-se também que $50 \%$ das empresas entrevistas consideram que se os resíduos produzidos por suas obras forem depositados de forma irregular podem causar um médio impacto ao meio ambiente, fato que provocar uma atenção maior por parte dos órgãos de controle ambiental no tocante à informação e conscientização dos danos que a deposição irregular dos RCD pode causar ao meio ambiente.

Figura 3: Impacto causado pela geração de RCD no canteiro de obras

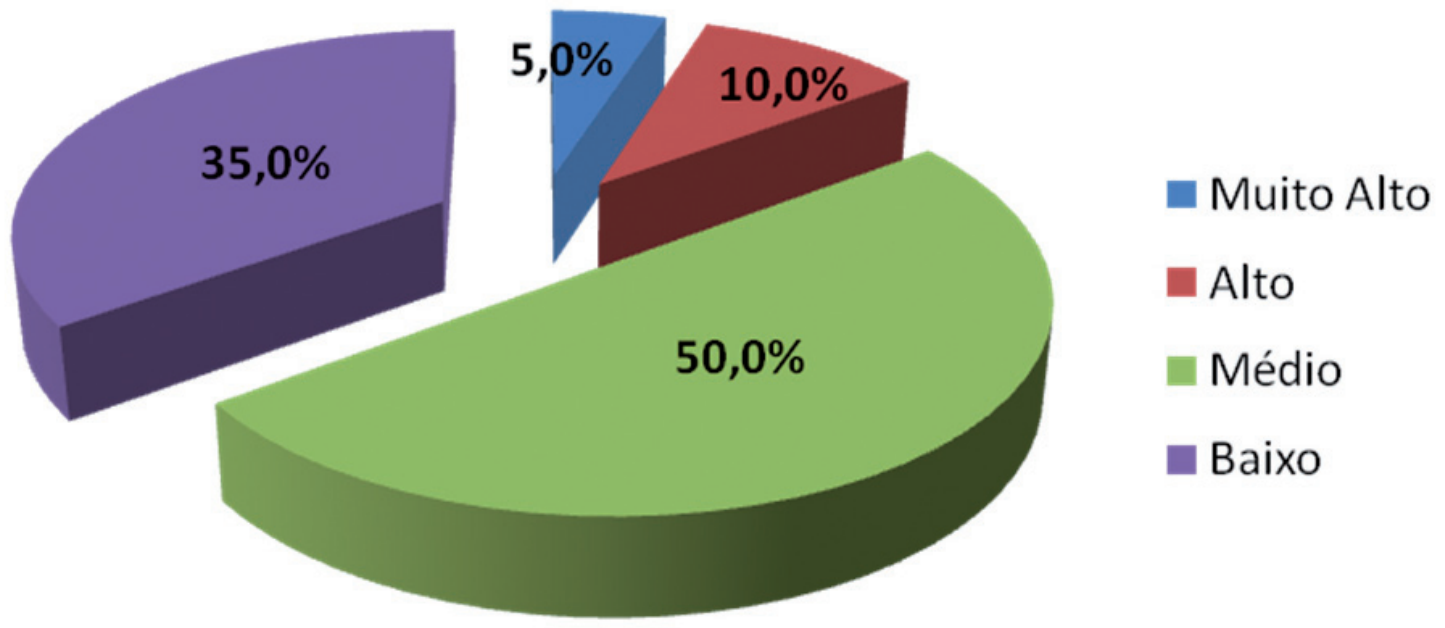

Fonte: Dos autores (2011) 
Quanto às empresas coletoras de RCD, duas se localizam no Município de Juazeiro do Norte e uma no Município de Crato. O número de containeres utilizados para a coleta em cada empresa é variável, sendo que as situadas em Juazeiro do Norte possuem em torno de 70 containeres cada e a localizada na cidade de Crato possui 50 unidades. A quantidade de containeres coletados por mês varia de empresa para empresa, sendo que em Juazeiro do Norte uma empresa coleta em torno de 250 caçambas e a outra em torno de 200 caçambas. Já no município de Crato, são coletadas em torno de 300 containeres. Todos esses resíduos coletados de acordo com as três empresas entrevistadas são depositados no aterro das cidades de Crato e Juazeiro do Norte, servindo como camada de cobertura dos resíduos sólidos coletados em toda a cidade, não chegando a ser considerado um aterro controlado uma vez que não há a aplicação das técnicas recomendadas para este tipo de tratamento de resíduos.

Quanto à existência de áreas para descarte de RCD apenas a cidade de Juazeiro do Norte possui áreas cadastradas pela Secretaria de Meio Ambiente e Serviços Públicos - SEMASP e apropriadas para descarte dos resíduos por parte das empresas coletoras, caçambeiros e carroceiros.

No entanto, já se verificam a adoção de algumas medidas para se coibir a disposição de RCD em áreas não cadastradas, portanto irregulares. A SEMASP possui legislação específica para aplicação de multa e apreensão dos veículos transportadores. No tocante à proibição de se colocar resíduos nos passeios públicos os três municípios possuem legislação específica que prevê aplicação de multa para os proprietários dos imóveis que não recolherem os resíduos produzidos por obras ou demolições, bem como para aqueles que utilizam os passeios públicos para depósitos de materiais de construção.

Entre as principais diretrizes sugeridas por esse trabalho para se alcançar o desenvolvimento sustentável da construção civil na Região Metropolitana do Cariri, destacam-se:

a) Capacitação de agentes que possam iniciar um trabalho de base, praticar a interação entre a sociedade e o poder público, a partir do contato com associações de bairros, escolas, igrejas, Organizações Não Governamentais ONG's, dentre outros, buscando captar os multiplicadores, ou seja, indivíduos que possam colaborar na divulgação dos programas propostos pelo município, promover a conscientização da sociedade para que esta também venha a contribuir para a minimização dos problemas causados pelos RCD;

b) Desenvolvimento de material elucidativo aos diversos agentes, que garanta divulgação e a multiplicação das ações educativas. Esse material poderá ser na forma de cartilhas, painéis, folders, outdoors dentre outros. $O$ incentivo ao não descarte do entulho é extremamente importante no combate às áreas de deposição dos RCD; 
c) Tomando o exemplo de iniciativas bem sucedidas em Belo Horizonte, uma proposta que pode ser viabilizada é a isenção da taxa do habite-se para obras cujos resíduos tenham sido comprovadamente encaminhados, numa primeira instância, às Centrais de Entulho, posteriormente, à central de reciclagem;

d) Articulação dos diferentes agentes envolvidos (pequenos geradores, grandes geradores, transportadores de RCD, entes públicos) nas atividades vinculadas com a indústria da construção civil para redução do seu impacto ambiental;

e) Ação indutora do setor público para utilização de materiais reciclados, exercendo o seu poder de compra e estabelecendo a obrigatoriedade de utilização de agregados reciclados em obras públicas, construindo parcerias com a iniciativa privada, com as associações de catadores e entre municípios conturbados.

\section{CONCLUSÃO}

É imprescindível que sejam implantadas ações de políticas públicas por parte da Administração Municipal para a gestão sustentável dos RCD. É igualmente necessária a adoção de instrumentos legais e reguladores que norteiem e garantam a sustentação legal, política e econômica à elaboração de um Plano de Gerenciamento dos RCD da Região Metropolitana do Cariri. É necessário que o poder público, em todas as esferas de governo saia da letargia que lhe é peculiar e avance na implementação de políticas públicas capazes de romper barreiras jurídicas e promover a articulação entre todos os órgãos da administração pública, para garantir consolidação e continuidade dos projetos com medidas eficientes de fiscalização além de incentivos aos geradores de RCD.

Além destas medidas, outras deverão ser adotadas para minimizar o problema, como a diminuição da geração de RCD, a deposição em áreas apropriadas, a coleta seletiva de resíduos em canteiros de obras, a reciclagem dos RCD, a Educação Ambiental nas empresas e canteiro de obras e inserção de disciplina de sustentabilidade e meio ambiente na matriz curricular dos cursos técnicos e superior das áreas ligadas à engenharia. Tais ações deverão ser voltadas ao esclarecimento e ensinamento da população em relação aos resíduos de construção e demolição (geração, deposição, transporte, destinação final adequada), os impactos ambientais e sociais causados pela deposição irregular desses resíduos em terrenos baldios, margem de córregos (Áreas de Preservação Permanente - APP's), vias públicas, entre outros, bem como o desenvolvimento de ações que visem à redução, controle e fiscalização das áreas para disposição dos RCD o que, sem sobra de dúvidas, favorecerá para o crescimento sustentável da construção civil na Região Metropolitana do Cariri. 
Diante de tantos problemas ambientais verificados na Região Metropolitana do Cariri durante a realização desse trabalho, acredita-se que o objetivo proposto foi parcialmente atendido, pois a implementação das diretrizes aqui propostas dependerá da consciência pela responsabilidade socioambiental por parte de todos os atores sociais envolvidos na cadeia produtiva da construção civil.

\title{
MANAGEMENT OF THE CONSTRUCTION AND DEMOLITION WASTE: GUIDELINES FOR SUSTAINABLE GROWTH OF CONSTRUCTION IN THE METROPOLITAN REGION OF CARIRI CEARENSE
}

\begin{abstract}
The population growth, industry advancements and urbanization have contributed to the increased generation of Construction and Demolition Waste - CDW, that are released into the environment, at least which is the point data collected in several Brazilian cities where the CDW is more than $50 \%$ of the mass of municipal solid waste. The construction industry has some special features, and among its main features are the high wastage and environmental impact caused by the large volume of waste generated and the large quantity of raw material consumed, is cause for many discussions on the need to pursue development sustainable. This work contributes to the solution of this problem, specifically with regard to combating waste generation, as it makes an accurate diagnosis and presents some guidelines for the sustainable growth of construction in the Metropolitan Region of Cariri. The methodology used in this study consisted of literature review, identifying key points of deposition and estimate the amount of the $\mathrm{CDW}$, identification of environmental impacts caused by the irregular deposition of CDW and enforcement of existing environmental legislation. To obtain data, a checklist was applied, interviews made, exploratory visits and photographs. The main results of the research show that the entities involved in environmental issues of the Metropolitan Region of Cariri have a modest knowledge of specific environmental legislation that does not exist in the region and an efficient model of environmental management or control over the allocation of the CDW. It was also found that most respondents said they did not know the fate of his works produced in CDW.
\end{abstract}

Key-words: Construction and Demolition Waste. Management. Environmental Impacts. Sustainable Development. 


\section{REFERÊNCIAS}

ÂNGULO, S. C. Caracterização de agregados de resíduos de construção e demolição reciclados e a influência de suas características no comportamento de concretos. 2005. 236 f. Tese (Doutorado)-Escola Politécnica da Universidade de São Paulo, São Paulo, 2005.

BRASIL. Conselho Nacional do Meio Ambiente - CONAMA. Resolução no. 307, de 05 de julho de 2002. Estabelece diretrizes, critérios e procedimentos para a gestão dos resíduos da construção civil. Brasília. Publicação Diário Oficial da União, no 136, de 17/07/2002, p. 95-96.

BRASIL. Constituição República Federativa do Brasil 1988. Brasília (DF): Senado Federal, 1988. xv, 292 p.

CARNEIRO, A. P. et al. Características do entulho e do agregado reciclado. In: CARNEIRO, A. P.; BRUM, I. A. S.; CASSA, J. C. S. Reciclagem de Entulho para Produção de Materiais de Construção: projeto entulho bom. Salvador: EDUFBA, 2001. Cap.5, p.142-187.

FERREIRA, D. D. M.; NOSCHANG, C. R. T.; FERREIRA, L. F. Gestão de Resíduos da Construção Civil e de Demolição: Contribuições para a Sustentabilidade Ambiental. In: CONGRESSO NACIONAL DE EXCELÊNCIA EM GESTÃO, 5., 2009. Niterói, RJ. Anais... Niterói, RJ, 2009.

FREITAS, I, M. Os Resíduos de Construção Civil no Município de Araraquara-SP. 2009. 86 f. Dissertação (Mestrado)-Centro Universitário de Araraquara - UNIARA, Araraquara, 2009.

GAEDE, L. P. F. Gestão dos resíduos da construção civil no município de Vitórias-ES e normas existentes. 2006. 74 f. Monografia (Especialização em Construção Civil)- Escola de Engenharia UFMG, Belo Horizonte, UFMG, 2006. Disponível em: http://www.cecc. eng.ufmg.br/trabalhos/Monografia Lia - final.pdf. Acesso em: 23 maio 2011.

MARQUES NETO, J. C. Gestão dos resíduos da construção e demolição no Brasil. 2005. 162 f. Tese (Doutorado)- Universidade de São Paulo, São Carlos, 2005.

MEDEIROS, J. D. Avaliação de Impacto Ambiental. In: REUNIÃO ANUAL DA SOCIEDADE BRASILEIRA PARA O PROGRESSO DA CIÊNCIA, 47. 1995, São Luis. Anais... São Luis: Universidade Federal do Maranhão - UFM, 1995. p. 47

PINTO, T. P. De Volta à Questão do Desperdício. Construção, São Paulo, n. 271, p. 34-35, dez. 1995.

SANTOS, A. Método de intervenção em obras de edificações enfocando o sistema de movimentação e armazenamento de materiais: um estudo de caso. 1995, $140 \mathrm{f}$. Dissertação (Mestrado)-Universidade Federal do Rio Grande do Sul, Porto Alegre, 1995. 
SANTOS, E. C. G. Aplicação de resíduos de construção e demolição reciclados (RCD-R) em estruturas de solo reforçado. 2007. 173 f. Dissertação (Mestrado)-Escola de Engenharia de São Carlos, Universidade de São Paulo, São Carlos, SP, 2007.

SINDICATO DA INDÚSTRIA DA CONSTRUÇÃO CIVIL-MG. Guia de Sustentabilidade na Construção. Belo Horizonte, 2008.

TAVARES, L. P. M. Levantamento e análise da deposição e destinação dos resíduos da construção civil em Ituiutaba, MG. 2007. 160 f. Dissertação (Mestrado)-Faculdade de Engenharia Civil, Universidade Federal de Uberlândia, Uberlândia, 2007.

\section{SOBRE OS AUTORES}

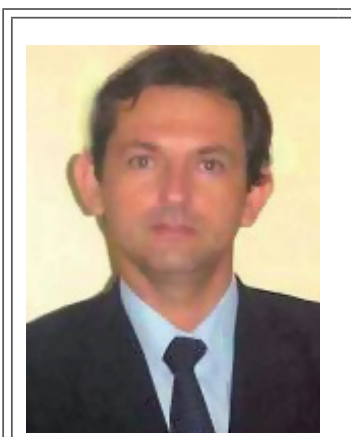

Jefferson Luiz Alves Marinho

Engenheiro Civil pela Universidade Federal do Ceará (UFC), Tecnólogo em Topografia e Estradas pela Universidade Regional do Cariri (URCA), Bacharel em Direito (URCA), Mestre em Engenharia e Tecnologia Ambiental pela Universidade de León - Espanha, Especialista em Administração de Empresas (URCA), Especialista em Engenharia de Segurança do Trabalho (Faculdade Leão Sampaio) e Especialista em Avaliações e Perícias de Engenharia (Faculdade Osvaldo Cruz-SP). É docente Adjunto do departamento de Construção Civil da URCA. É coordenador do Curso de pós-graduação em Gerenciamento da Construção Civil da URCA. Atua como perito em diversas varas da Justiça do Ceará. É diretor técnico da empresa ENGEAP - Avaliações e Perícias Ltda., prestando serviços para diversos órgãos públicos e empresas públicas e privadas.

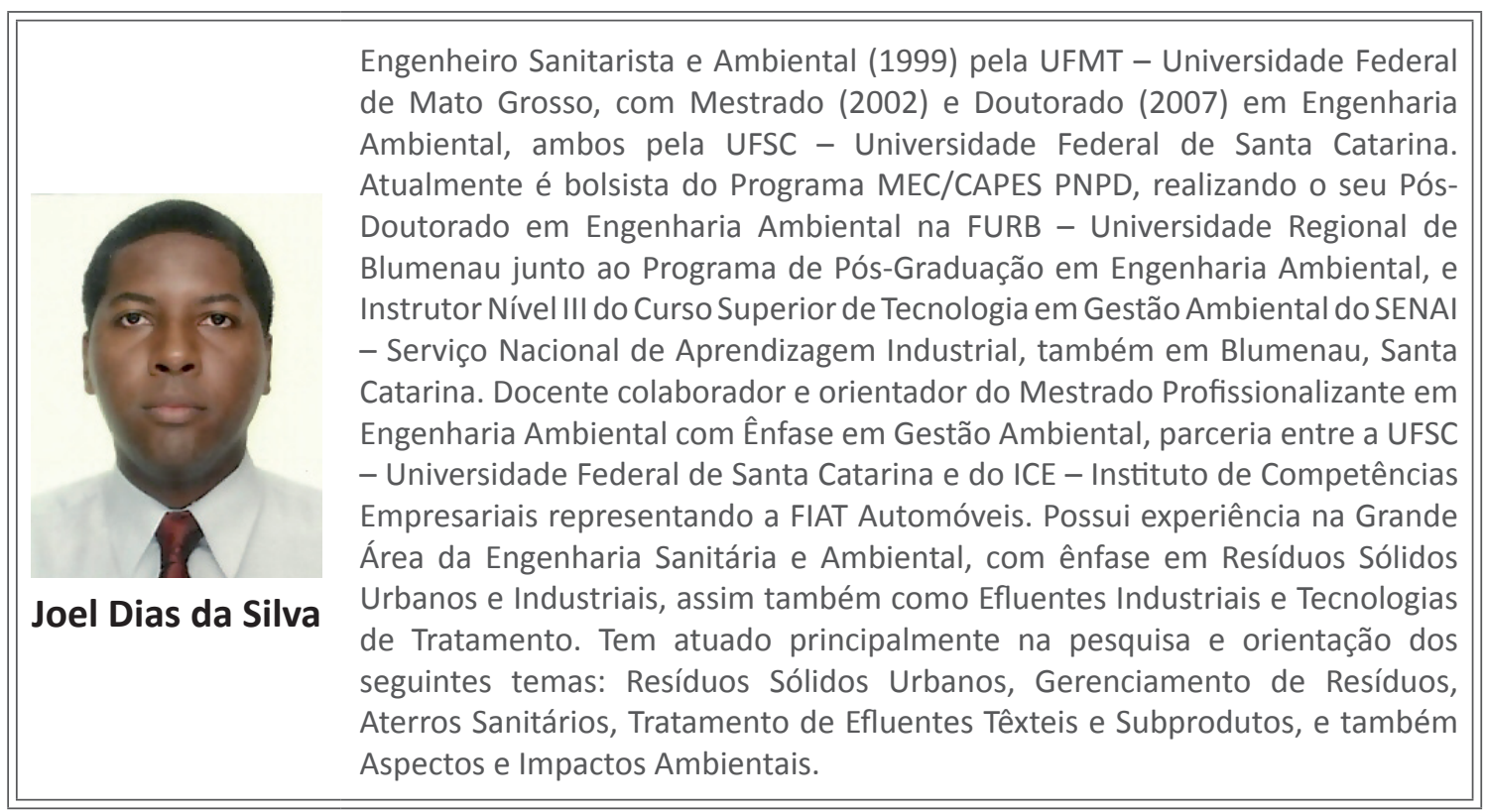

